TAO, Vol. 11, No. 3, 631-642, September 2000

\title{
Static Stress Transfer and Aftershock Triggering by the 1999 Chi-Chi Earthquake in Taiwan
}

\author{
Wei-Hau Wang ${ }^{1, \text { * }}$
}

(Manuscript received 20 March 2000, in final form 3 May 2000)

\begin{abstract}
The static stress changes caused by the Chi-Chimainshock with $M_{L}=7.3$ were analyzed with an elastic dislocation model in a homogenous half-space. The results show that most aftershocks in the fold-and-thrust belt might best be interpreted as the re-activation of pre-existing thrust faults triggered by the mainshock. Strike-slip motions near the terminations of the Chelungpu fault are also likely to have been enhanced by the static stress transfer. The Chukou fault, on the other hand, fell in a stress shadow; as a result, few aftershocks occurred there.

The Chia-Yi earthquake sequence which occurred a month after the Chi-Chi earthquake turns out to have been an exception in this study. No evidence of static stress enhancement was found in that area. Unless the large aftershocks which followed the Chi-Chi earthquake altered the stress field and promoted failure, the time lag of the Chia-Yi earthquake might well be attributed to the influence of a stress shadow.
\end{abstract}

(key words: Chi-Chi earthquake, Coulomb failure stress, Static stress changes)

\section{INTRODUCTION}

Taiwan is located at the active convergent boundary between the Eurasian and Philippine Sea plates. Collision of the two plates have frequently induced many large earthquakes and caused serious damage especially in eastern, northwestern and southwestern Taiwan. Compared to these highly vulnerable areas, central Taiwan, on the other hand, had been relatively inactive in terms of seismicity until 21 September, 1999 (local time), when a major earthquake with local magnitude of 7.3 struck the Taichung-Nantou area killing more than 2,500 people. In many places, this strong shock lasted more than 40 seconds and more than 980 gal. ground acceleration was experienced. With the mainshock, the Chelungpu fault, a reactive thrust fault, extending nearly $77 \mathrm{~km}$ in the North-south (NS) direction, ruptured the ground with a maxi-

\footnotetext{
${ }^{1}$ Institute of Applied Geophysics, National Chung Cheng University, Chia-Yi, Taiwan, ROC

${ }^{*}$ Corresponding author address: Prof. Wei-Hau Wang, Institute of Applied Geophysics, National Chung Cheng University, Chia-Yi, Taiwan, ROC; E-mail: seiwhwg@eq.ccu.edu.tw
} 
mum surface displacement of up to $3.4 \mathrm{~m}$ in the vertical direction and $9 \mathrm{~m}$ in the horizontal direction (Chung and Shin 1999). In the first three months after the mainshock, thousands of earthquakes occurred over a vast area as shown in Fig. 1. Why were these aftershocks distributed over such a wide area? Could they have been the result of the same kind of rupture mechanism? Were all of them triggered by the mainshock? These are the issues which are addressed in this paper.

Recent studies have indicated that static stress changes due to mainshocks would likely induce aftershocks on nearby faults where the Coulomb failure stress is increased (e.g., Reasenberg and Simpson 1992; King et al. 1994; Toda et al. 1998) but decelerate the seismicity rate in a region where the Coulomb failure stress is decreased (e.g., Harris and Simpson,. 1998). If so, analyzing the static stress changes induced from the Chi-Chi earthquake would be one key to answering the above questions. However, previous studies have also indicated that not all cases follow the static stress change triggering model. For instance, the Northridge (Hardebeck et al. 1998) and Loma Prieta earthquakes (Beroza and Zoback,. 1993; Kilb et al. 1997) show few signs of static stress triggering in aftershock sequences. Therefore, in order to better understand the effect of static stress transfer, this paper adopted a statistical method to test the hypothesis of static stress triggering in the Chi-Chi earthquake sequence.

\section{STATIC STRESS CHANGES CAUSED BY THE CHI-CHI EARTHQUAKE}

This study adopted the unilateral rupture model of Yagi and Kikuchi (1999) which had been derived from the inversion of teleseismic body waveforms. The rupture model was further simplified to 50 slip patches 10 by $10 \mathrm{~km}$ in size as shown in Fig. 2. The source mechanism of the mainshock given by the CMT short reference results suggests that the Chelungpu fault is oriented $\mathrm{N} 26^{\circ} \mathrm{E}, 27^{\circ} \mathrm{E}$ with fault slip along a rake of $82^{\circ}$. With this information, the static stress changes can be calculated by applying the finite source dislocation model (Okada 1992) on each fault patch in an elastic half-space with a shear modulus of $3 \times 10^{10} \mathrm{Nm}^{-2}$ and Poisson's ratio of 0.25 . The changes in static stress obtained from the above calculations were then converted into stress increments onto the fault planes in orthogonal directions (normal stress increments) and in the slip directions (shear stress increments) of the triggered earthquakes.

In the Coulomb failure criterion, failure occurs on a plane when the Coulomb failure stress (CFS) is zero; that is,

$$
\sigma_{c}=\tau+\mu\left(\sigma_{n}+p\right)-C,
$$

where $\sigma_{c}$ is the Coulomb failure stress; $\tau$ is the shear stress on the objective plane (in the slip direction); $\mu$ is the friction coefficient; $\sigma_{n}$ is the normal stress on the objective plane; $p$ is the pore fluid pressure; $C$ is the cohesion. If $\mu$ and $C$ are constant over time, the Coulomb failure stress changes ( $\triangle \mathrm{CFS}$ ) on a fault plane can then be determined as follows:

$$
\Delta \sigma_{c}=\Delta \tau+\mu\left(\Delta \sigma_{n}+\Delta p\right) .
$$




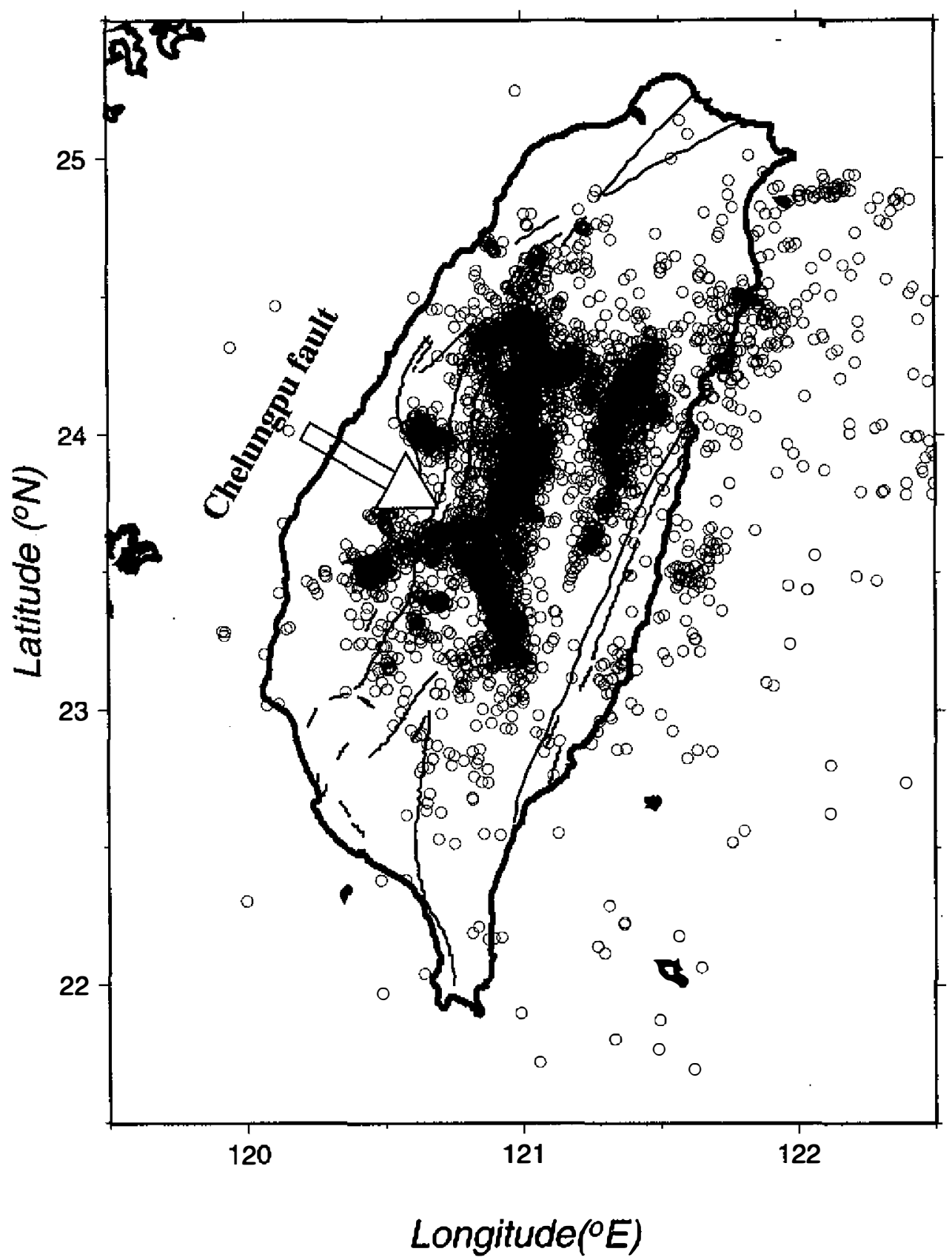

Fig. 1. Subsequent seismicty of the Chi-Chi earthquake from 22 September to 31 December, 1999 (Data provided by the Central Weather Bureau). The open circles indicate the locations of the aftershocks. Two N-S trending clusters of earthquakes east of the Chelungpu fault are separated by an aseismic Central Range. 


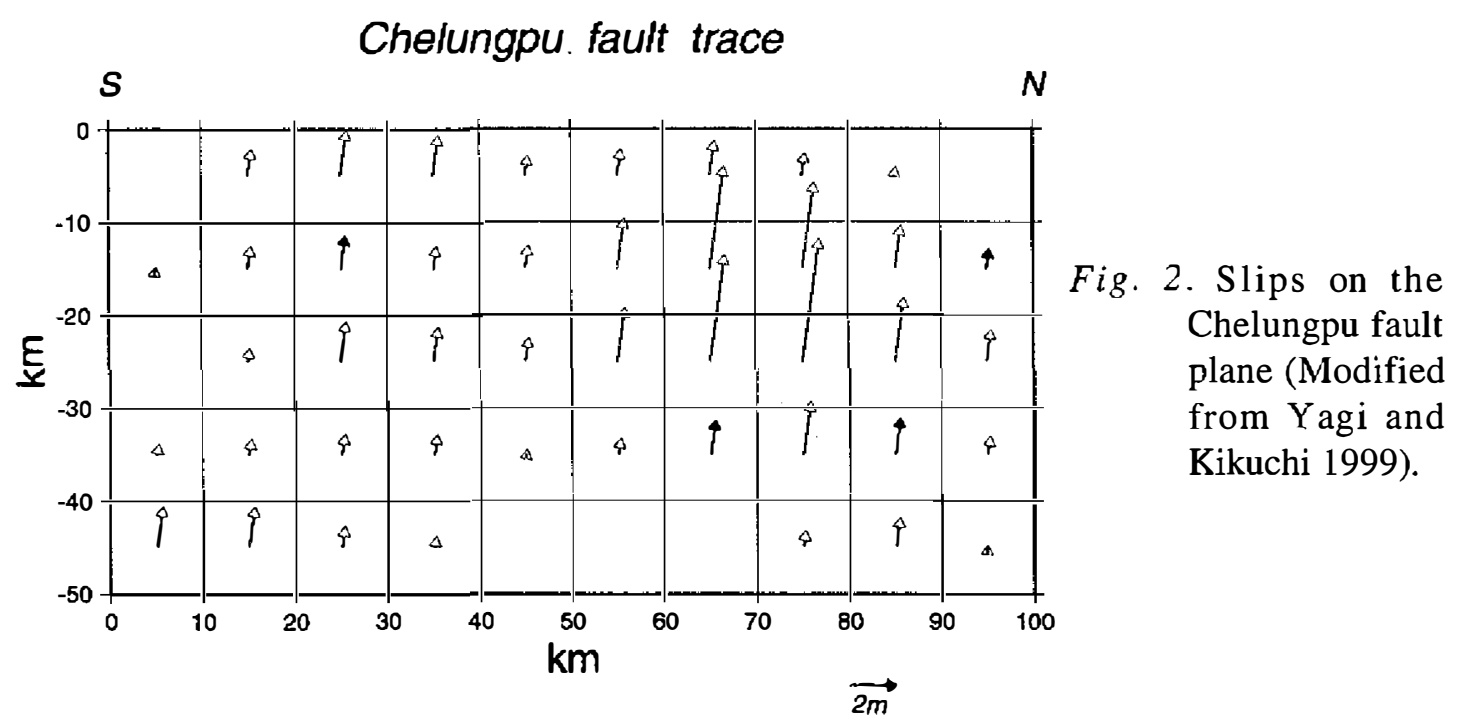

This equation is usually simplified to the following equivalent form by introducing the Skempton's coefficient $\beta$ :

$$
\Delta \sigma_{c}=\Delta \tau+\mu^{\prime} \Delta \sigma_{n}
$$

with

$$
\mu^{\prime}=\mu(1-\beta)
$$

where $\mu^{\prime}$ is the effective friction coefficient.

Theoretically, $\beta$ may range from 0 to 1 , but in fact it is usually from 0.7 to 1.0 (e.g., Green and Wang 1986). Strictly speaking, $\mu^{\prime}$ is not a constant but instead changes with time due to fluctuations in the pore fluid pressures induced by the stress step from the mainshock. Nevertheless, $\mu^{\prime}$ tends to be small in value (e.g., Gross and Burgmann 1998; Kagan and Jackson 1998). Deng and Sykes (1997) suggested a range of $\mu^{\prime}$ between 0 and 0.6. In this study, $\mu^{\prime}$ was assumed to be 0.4 , following King et al. (1994). Positive values of the $\Delta$ CFS promote failure or, in terms of rate-and-state dependent friction, increase the seismicity rate and vice versa (Dieterich 1994).

The attitude of the objective fault plane and the slip direction can be determined either from estimations based on geological observations and historical earthquake records, or from focal mechanisms of the aftershocks. Alternatively, if the background stress field prior to the mainshock is available with small faults distributed regionally in all orientations, the "optimal" fault planes that are most likely triggered by the static stress changes can be determined. However, because limited knowledge of the regional stress is currently available, this study tested the $\Delta \mathrm{CFS}$ on three types of faults, namely those with attitudes of $\mathrm{N} 10^{\circ} \mathrm{E}, 30^{\circ} \mathrm{E}$ (thrust), $\mathrm{N} 75^{\circ} \mathrm{W}, 90^{\circ}$ (left-lateral strike-slip), and $\mathrm{N} 75^{\circ} \mathrm{W}, 80^{\circ} \mathrm{S}$ (right-lateral strike-slip). These are the most commonly observed faults in the field and were inferred from focal mechanisms (e.g., Kao and Chen 2000). For each case, it was assumed that micro-faults with the same attitude 
were distributed all over the study area. Apparently, though, this is not the case in reality; as a result, none of these models alone could fully describe the rupture mechanisms for all the aftershocks even though thrust faults are more frequently observed in the mountain belt than are strike-slip faults. The relative significance among the models in a specific area relies on the agreement between the modeled ruptures and the focal mechanisms of the aftershocks.

Figures 3 to 5 illustrate the $\Delta$ CFS for thrusts at depths of $2.5,7.5$, and $12.5 \mathrm{~km}$, respectively. The common feature of these diagrams is that the $\triangle \mathrm{CFS}$ greatly increases in the area to the east of the Chelungpu fault. In other words, it was very likely that thrust faulting was

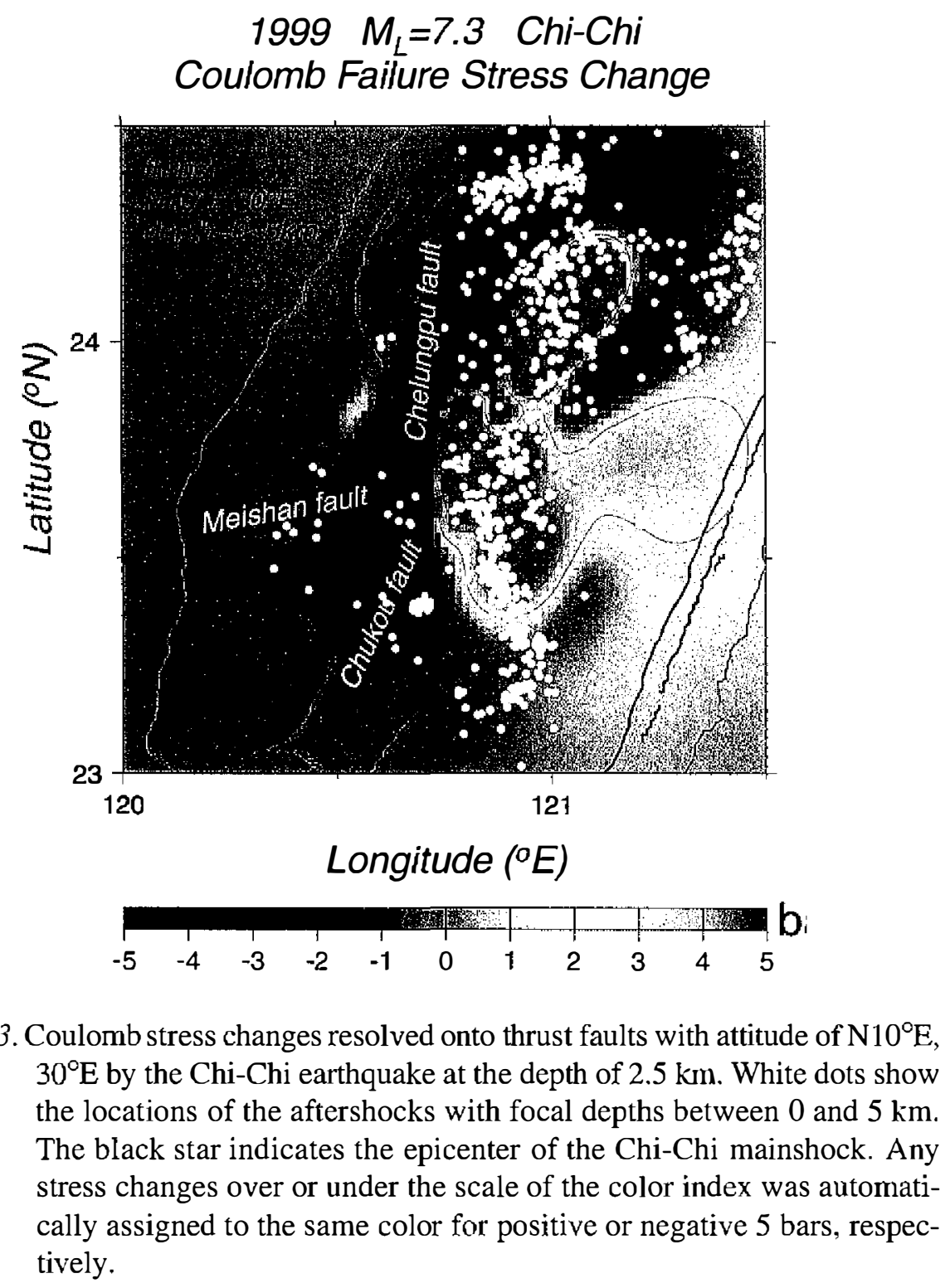

Fig. 3. Coulomb stress changes resolved onto thrust faults with attitude of $\mathrm{N} 10^{\circ} \mathrm{E}$, $30^{\circ} \mathrm{E}$ by the Chi-Chi earthquake at the depth of $2.5 \mathrm{~km}$. White dots show the locations of the aftershocks with focal depths between 0 and $5 \mathrm{~km}$. The black star indicates the epicenter of the Chi-Chi mainshock. Any stress changes over or under the scale of the color index was automatitively. 


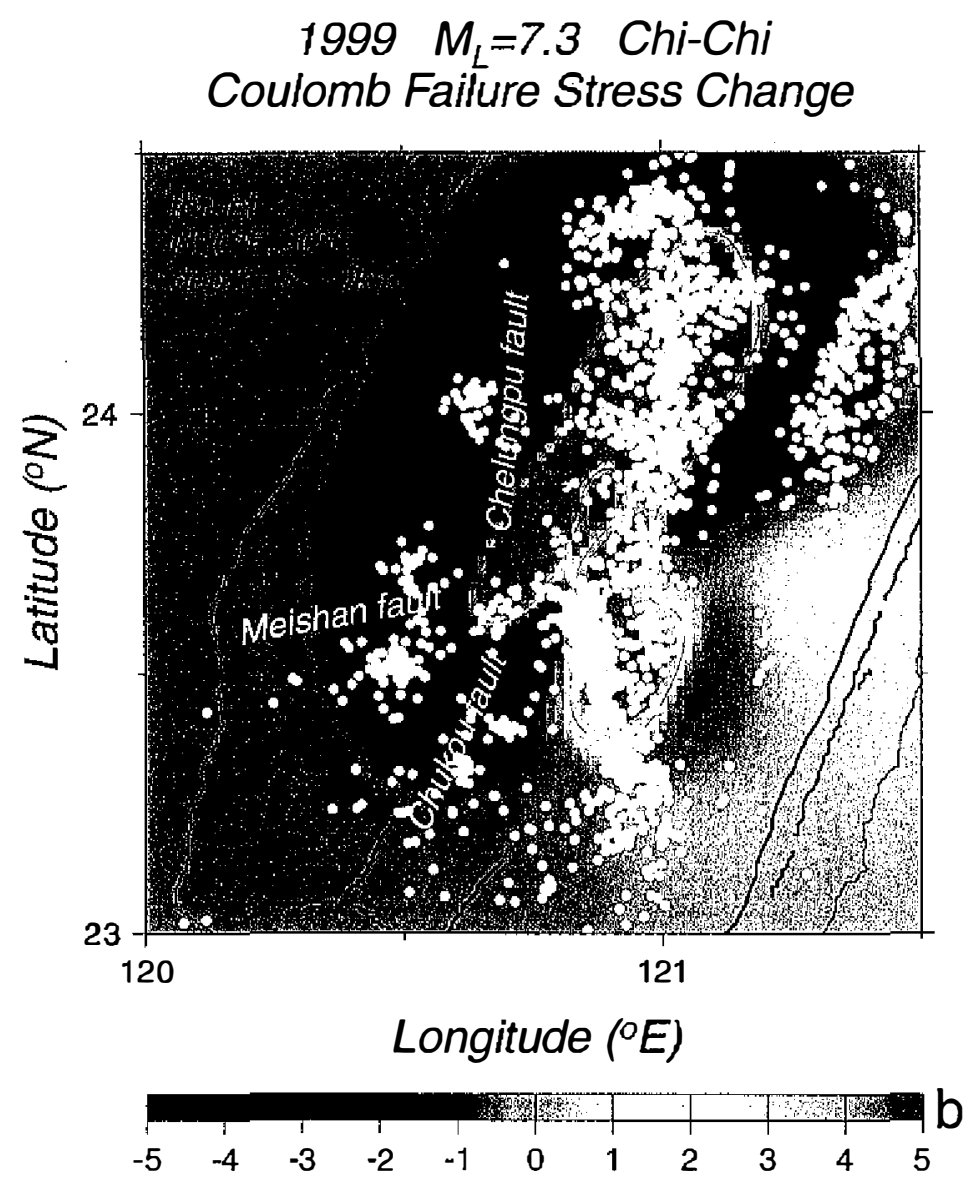

Fig. 4. Coulomb stress changes resolved onto thrust faults with attitude of $\mathrm{N} 10^{\circ} \mathrm{E}$, $30^{\circ} \mathrm{E}$ by the Chi-Chi earthquake at the depth of $7.5 \mathrm{~km}$. White dots show the locations of the aftershocks with focal depths between 5 and $10 \mathrm{~km}$.

triggered by the mainshock in this area. This inference is consistent with the focal mechanism suggested by Kao and Chen (2000). West of this stress-elevated zone, the $\Delta$ CFS becomes negative, indicative of a local stress shadow. Noteworthy is that the Chukou fault falls within this shadow zone, implying that the seismicity rate on the Chukou fault would decrease. In fact, fewer earthquakes were located in this shadow zone than in the stress-enhanced area.

Kao and Chen (2000) have suggested that the Chelungpu fault is bounded by NE trending, right-lateral strike-slip faults to the north and NW trending, left-lateral strike-slip faults to the south. Figure 6 shows the $\Delta$ CFS for the right-lateral strike-slip faults. Unlike previous calculations, the $\triangle \mathrm{CFS}$ in this case is positive in the area near the northern termination of the Chelungpu fault. As a result, more earthquakes agree with the static stress triggering model. It is also worth noting that the Meishan fault, southwest of the Chelungpu fault, has the same orientation but falls in a stress shadow. This implies that right-lateral strike-slip movement 


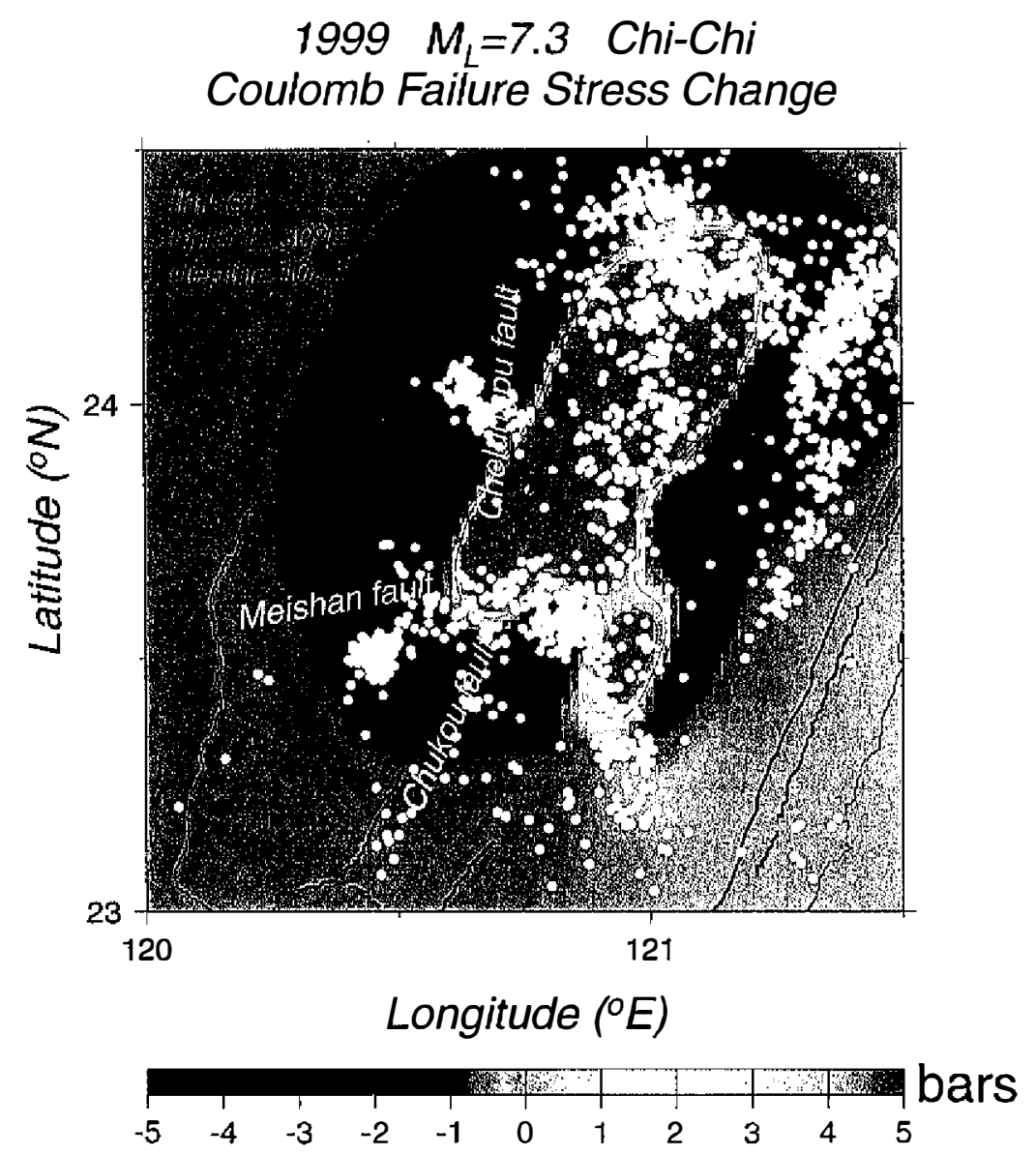

Fig. 5. Coulomb stress changes resolved onto thrust faults with attitude of $\mathrm{N} 10^{\circ} \mathrm{E}$, $30^{\circ} \mathrm{E}$ by the Chi-Chi earthquake at the depth of $12.5 \mathrm{~km}$. White dots show the locations of the aftershocks with focal depths between 10 and $15 \mathrm{~km}$.

along the Meishan fault was not likely to have been triggered by the Chi-Chi mainshock. Similarly, the $\triangle \mathrm{CFS}$ for left-lateral strike-slip faults at the depth of $7.5 \mathrm{~km}$ (Fig. 7) suggests a stress-enhanced belt associated with a cluster of aftershocks near the southern end of the Chelungpu fault. This feature supports Kao and Chen's findings.

Although most aftershocks were distributed in the stress-enhanced region, there were exceptions. For instance, northwest of the mainshock, a cluster of earthquakes in the foreland near the central portion of the Chelungpu fault fell into a stress shadow zone (see Fig. 4). This inconsistency may be from some error in identifying the type of objective fault that was assumed in the stress calculations. Kao and Chen (2000) found several normal rather than thrusting events in this area, which suggests that this area was experiencing extension, and not compression. The unexpected number of normal events, likely in response to the elastic re- 


\section{$1999 \quad M_{L}=7.3$ Chi-Chi Coulomb Failure Stress Change}

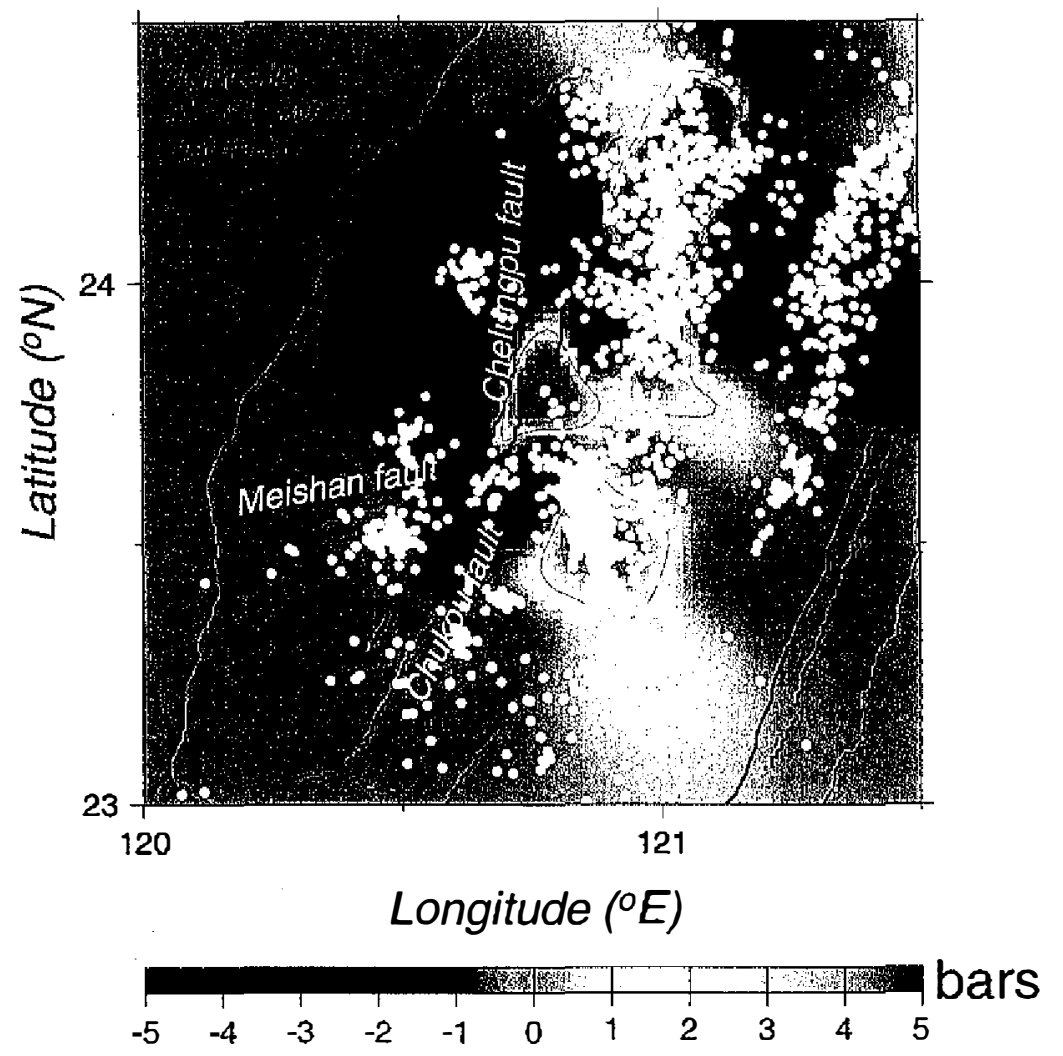

Fig. 6. Coulomb stress changes resolved onto right-lateral strike-slip faults with attitude of $\mathrm{N} 75^{\circ} \mathrm{E}, 80^{\circ} \mathrm{S}$ by the Chi-Chi earthquake at the depth of 7.5 $\mathrm{km}$. White dots show the locations of the aftershocks with focal depths between 5 and $10 \mathrm{~km}$.

bound and crustal bending due to the co-seismic loading of the westward migrating thrust sheet, has not yet been considered in the calculations. As a result, the triggering model for thrusts fails in this area.

Another cluster of earthquakes that does not agree with the positive $\triangle \mathrm{CFS}$ was the ChiaYi earthquake sequence which occurred one month after the Chi-Chi earthquake. This earthquake sequence was very closely located on the southern side of the Meishan fault. Of interest is that all of the calculations for either the thrust or strike-slip faults (see Figs. 4, 6 and 7) suggest a stress shadow in this area. There are two likely interpretations for the failure of the static stress triggering model. First, the Chi-Chi earthquake might have actually relaxed the active faults near Chia-Yi therby delaying subsequent earthquakes in that area. That is, the Chia-Yi earthquake might very well have occurred in the time span between September 21 

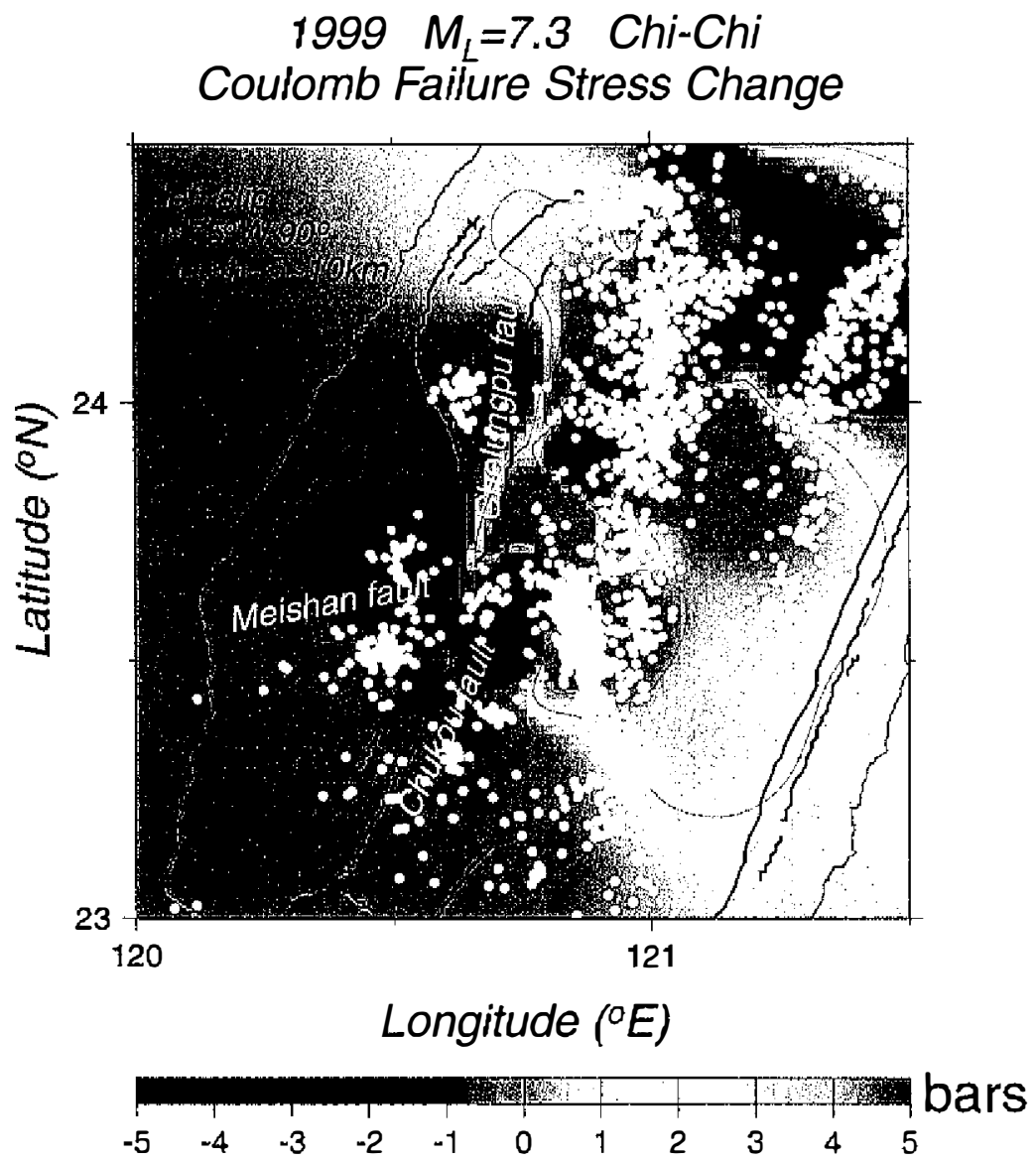

Fig. 7. Coulomb stress changes resolved onto left-lateral strike-slip faults with attitude of $N 75^{\circ} \mathrm{W}, 90^{\circ}$ by the Chi-Chi earthquake at the depth of $7.5 \mathrm{~km}$. White dots show the locations of the aftershocks with focal depths between 5 and $10 \mathrm{~km}$.

and October 22, 1999 had the Chi-Chi earthquake not disturbed the region. Alternatively, the Chia-Yi earthquake might not have been triggered by the Chi-Chi mainshock, as implied by its static stress changes, but by the following large aftershocks. For instance, four hours after the mainshock, a large aftershock with $M_{L}=6.5$ was located in the region about $40 \mathrm{~km}$ to the east of the Chia-Yi earthquake. This event might have further disturbed the stress field around Chia-Yi and induced the earthquake. This puzzle will be clarified when subsequent disturbance from the aftershocks of the Chi-Chi earthquake is quantitatively evaluated.

Still another inconsistency comes from the NNE-trending earthquake cluster in the eastern flank of the Central Range, which is separated from the stress-enhanced zone in the foldand-thrust belt by an aseismic zone along the crest of the Central Range. Kao and Chen (2000) have found that both normal and strike-slip faulting instead of thrusting have occurred in this 
belt. The complexity of the rupture mechanisms would cause the failure of any triggering model proposed earlier that calculates the $\triangle \mathrm{CFS}$ on just one kind of rupture.

\section{EFFECT OF STRESS TRANSFER ON AFTERSHOCKS}

Totally, 6,810 aftershocks occurring during the period from September 21 to December 31 were used to evaluate the possibility that the aftershocks had been triggered by the static stress changes due to the Chi-Chi earthquake. The judgement was based on the significance level with which one can reject the null hypothesis that aftershocks are independent of the static stress changes induced by the Chi-Chi earthquake. The null hypothesis implies the possibility of 0.5 for an individual event to fall into the region with the positive $\triangle \mathrm{CFS}$ and a binomial possibility density function for the number of events that agree with the positive $\triangle \mathrm{CFS}$. Because thrust faulting is the most common type of rupture observed in the fold-andthrust belt, the $\triangle \mathrm{CFS}$ referred to below is only for thrusts with attitude of $\mathrm{N} 10 \mathrm{E}, 30 \mathrm{E}$. The results indicate that 4,453 out of the 6,810 aftershocks fell within the region with the positive $\triangle \mathrm{CFS}$. In other words, $65 \%$ of the aftershocks agree with the static stress triggering model. In a standard right-side test (e.g., Kreyszig 1979), the corresponding significance level of the test is less than $0.01 \%$. This means that the possibility of the number of aftershocks agreeing with a positive $\triangle \mathrm{CFS}$ to be equal or larger than 4,453 is less than $0.01 \%$ if the null hypothesis stands. This value of significance level is much smaller than a frequent choice of significance level of 5\%; thus, the null hypothesis is rejected.

\section{DISCUSSION}

Although static stress triggering seems very promising in the case of the Chi-Chi earthquake sequence, there are several aspects that need to be improved upon in the future. First is the rupture model. The rupture model adopted in this preliminary study was inferred from teleseismic body waveforms. A better rupture model with higher resolution of the rupture characteristics can be derived from near-field strong motions recorded by dense broadband seismograph stations all over the island. Secondly, the Chelungpu fault should be modeled as a multi-segmented thrust to account for the fact that the strike of the fault changes from N-S to E-W near the northern end of the fault. This consideration has not yet been taken into account in this paper, which may have led to a misinterpretation of static stress transfer around the northern termination of the Chelungpu fault. The assumption of unilateral slips on every fault patch of the Chelungpu fault is also not very reasonable in light of the GPS observations by Hwang et al. (1999), who indicated slip vectors changing directions along the Chelungpu fault trace. A variable slip model is therefore required.

Other than the fracture model, rock rheology is another aspect to be considered. The aseismic Central Range might reflect ductile deformation within the deep crust. Viscoelastic or elastoplastic analyses need to be applied to that area. This is important especially for longterm triggering (e.g., Pollitz and Sacks 1997) which cannot be explained by elastic analyses. 
Coseismic changes in ground water tables from $7 \mathrm{~m}$ up to $11 \mathrm{~m}$ down (Hwang et al. 1999) imply that pore fluid pressures were greatly disturbed by the Chi-Chi earthquake. Because changes in pore fluid pressures would affect the effective friction coefficient and consequently the static stress changes, a simulation of the fluctuations of pore fluid pressures with poroelastic analyses is required so as to obtain a more accurate calculation for the $\triangle \mathrm{CFS}$. Finally, a recent $\mathrm{Vp} / \mathrm{Vs}$ study suggests that lateral heterogeneity is distinct in this area (C.-H. Chen, personal communication). The influence of lateral heterogeneity on the $\Delta \mathrm{CFS}$ must be evaluated in future studies.

Because a limited number of fault plane solutions is currently available, this paper considered only three kinds of ruptures for subsequent seismicity. The uncertainty arising from this simplification can be reduced when more focal mechanisms of the aftershocks are available so that static stress changes can be directly tested on the nodal planes of each event instead of on the objective faults inferred from geologic observations.

\section{CONCLUSIONS}

The static stress changes induced by the Chi-Chi mainshock suggest that most aftershocks in the fold-and-thrust belt were triggered by the mainshock. The Chia-Yi earthquake sequence is an exception. In fact, there is no direct evidence that the static stress changes induced by the Chi-Chi earthquake were able to trigger the Chia-Yi earthquake sequence. This, however, does not exclude the possibility that the static stress changes from later large aftershocks of the $\mathrm{Chi}$-Chi earthquake sequence further altered the stress field and promoted failure in the ChiaYi area. The seismogenic Chukou fault that has caused a great deal of severe damages throughout history was relatively quiet during this event since the Chi-Chi earthquake actually reduced the Coulomb failure stress on the fault plane.

Several aspects need to be considered in future studies. The rupture model can be greatly improved by incorporating vary-direction slips, strong-motion waveforms and multiple-attitude rupture planes. Viscoelastic deformation is particularly important to analyze static stress changes around the Central Range. Pore fluid pressure changes have such a great influence on the effective friction coefficient that the poroelastic effect should also be taken into consideration. With these improvements, it will be possible to better understand the effect of static stress transfer and estimate the possibility of future large earthquakes.

Acknowledgements The author acknowledges Chau-Huei Chen for broad discussions on many aspects of this research. Thanks also go to Chen-Hung Chen for preparing the diagrams and Shi-Chong Wen for helping to key in the dislocation program. The author is also grateful to two anonymous reviewers for their valuable comments on improving the manuscript.

\section{REFERENCES}

Beroza, G. C., and M. D. Zoback, 1993: Mechanism diversity of the Loma Prieta aftershocks and the mechanics of mainshock-aftershock interaction. Science, 259, 210-213.

Chung, J.-K., and T.-C. Shin, 1999: Implications of the rupture process from the displacement 
distribution of strong ground motions recorded during the 21 September 1999, ChiChi, Taiwan earthquake. TAO, 10, 777-786.

Deng, J., and L. R. Sykes, 1997: Stress evolution in southern California and triggering of moderate-, small-, and micro-size earthquakes. J. Geophys. Res., 102, 24411-24435.

Dieterich, J., 1994: A constitutive law for rate of earthquake production and its application to earthquake clustering. J. Geophys. Res., 99, 2601-2618.

Green, D. H., and H. F. Wang, 1986: Fluid pressure response to undrained compression in saturated sedimentary rock. Geophysics, 51, 948-956.

Gross. S., and R. Burgmann, 1998: The rate and state of background stress estimated from the aftershocks of the 1989 Loma Prieta, California earthquake. J. Geophys. Res., 103, 4915-4927.

Hardebeck, J. C., J. J. Nazareth, and E. Hauksson, 1998: The static stress change triggering: Constraints from two southern California aftershock sequences. J. Geophys. Res., 103, 24427-24437.

Harris, R. A., and R. W. Simpson, 1998: Suppression of large earthquakes by stress shadows: A comparison of Coulomb and rate-and-state failure. J. Geophys. Res., 103, 2443924451.

Hwang, C.-Y., C.-W. Lin, W.-S. Chen, Y.-K. Chen, S.-B. Yu, Y.-P. Chia, M.-T. Lu, C.-H. Ho, and Y.-S. Wang, 1999: The Chi-Chi earthquake and Chelungpu earthquake fault, Central Taiwan (in Chinese), International workshop on Chi-Chi Taiwan earthquake of Sept. 21, 1999, Nat. Sci. Council, 9-20.

Kagan, Y. Y., and D. D. Jackson, 1998: Spatial aftershock distribution: Effect of normal stress. J. Geophys. Res., 103, 24453-24467.

Kao, H., and W.-P. Chen, 2000: The Chi-Chi earthquake sequence of September 20, 1999 in Taiwan: Seismotectonics of an actice, out-of-sequence thrust, submitted to Science.

Kilb, D., M. Ellis, J. Gomberg, and S. Davis, 1997: On the origin of diverse aftershock mechanisms following the 1989 Loma Prieta earthquake. Geophys. J. Int., 128, 557-570.

King, G. C. P., R. S. Stein, and J. Lin, 1994: Static stress changes and the triggering of earthquakes. Bull. Seismol. Soc. Am., 84, 935-953.

Kreyszig, E., 1979: Advanced engineering mathematics, John Wiley \& Sons, 939 pp.

Okada, Y., 1992: Internal deformation due to shear and tensile faults in a half-space. Bull. Seism. Soc. Am., 82, 1018-1040.

Pollitz, F. F., and I. S. Sacks, 1997: The 1995 Kobe, Japan, earthquake: A long-delayed aftershock of the offshore 1944 Tonankai and 1946 Nankaido earthquakes. Bull. Seismol. Soc. Am., 87, 1-10.

Reasenberg P. A., and R. W. Simpson, 1992: Response of regional seismicity to the static stress change produced by the Loma Prieta earthquake. Science, 255, 1687-1690.

Toda, S., R. S. Stein, P. A. Reasenberg, J. H. Dieterich and A.Yoshida, 1998: Stress transferred by the $1995 \mathrm{Mw}=6.9$ Kobe, Japan, shock: Effect on aftershocks and future earthquake probabilities. J. Geophys. Res., 103, 24543-24565.

Yagi, Y., and M. Kikuchi, 1999: Spatiotemporal distribution of a source rupture process for the Taiwan earthquake (Ms=7.7), at http://wwweic.eri.u-tokyo.ac.jp/yuji/taiwan/ taiwan.html/. 